last week for a fuller and more technical justification of these points are entirely in the right.

What of the more distant future? The Post Office is already the most prolific investor of all the British nationalized industries--the nearest competitor, the electricity industry, is now making do with just over $\mathfrak{4} 400$ million a year. But in the 1980 s, the Post Office will surpass its present performance, for then there will be an urgent need to build a new high capacity trunk network and to begin work on the provision of digital communications to subscribers of all kinds. A decade from now, the complaint will be that the Post Office has not invested sufficiently in wide-band links for business and even domestic subscribers and that its capacity to do so is restricted by the technical character of the exchange equipment still being installed or soon to be installed. It is not therefore entirely impolite to ask whether there might not be advantages in postponing some of the development now planned for the sake of the chance to invest in still more powerful and presumably profitable equipment ten years from now. It is true that such a strategy would imply a less rapid improvement of the telecommunications network than now seems likely, but it is at least an option that deserves some public discussion by the shareholders. It is also proper, if openly impolite, to ask whether the Post Office Corporation could have sustained its present programme of development with equipment bought off the shelf from suppliers on the mainland of Europe. There is at least a suspicion that the old chauvinism lingers on.

The House of Commons is also well placed to ask some searching questions about the Post Office Corporation's relations with its customers. Britain is distinguished from other industrial nations by the small percentage of telephones in use which belong to personal as distinct from business subscribers and by the poor usage of telephones by private customers. By all accounts, the corporation would like to see these habits changed but has not been especially vigorous in its attempts to change them. There are quite substantial charges to be paid by those who ask for the privilege to become telephone subscribers when thoroughly commercial operators would seek to recover the costs of installing new telephones and telephone lines from the business that they would generate. And there are charges made for even the first calls made in every quarter when an out-and-out commercial policy aimed at a fuller use of the capital investment would lump a free quota of calls in with the usual rental fee. And little has been heard, in Britain, of the use of the telephone system as a social service although it has been recognized elsewhere, in New York for example, that old people and the sick are even more urgently in need of access to a telephone than the wellto-do. These again are issues on which the House of Commons deserves a detailed explanation. Sir John Eden should provide it.

\section{Inners and Outers}

Professor Herman Bondis committee on the mobility of scientists between government departments on the one hand and industry and the universities on the other (see page 120) is entirely laudable, but neither he nor his wellwishers should be disappointed if very little is achieved. The Fulton commission on the civil service, now four years old, did much to dramatize the need for mobility of this kind, and there is no doubt much that could be done to remove the impediments which at present restrict the movement of people. To set out, as Professor Bondi has done, to make pension rights transferable, both for those who leave the civil service and those who enter it for short periods, is a necessary first step. But if the object of Professor Bondi's exercise is to make it seem attractive to gifted people to take up short commissions in the civil service, much more than this will be needed. The experience of the Administration in the United States is a good illustration of what is necessary. The enlivenment of the United States government by the steady stream of enterprising people from outside now envied by the Civil Service Department is possible only because people joining the United States government for short periods can hope that they will nevertheless be able to do a tangible and useful job and in the process wield political influence of a sort. In the British government's attempt to strengthen the Chief Scientists' organizations of government departments, it is clear that there will be many potential openings of this kind. But is there any chance that the civil service will allow these to be posts in which scientists from outside might feel free to act constructively?

\section{Yeurs Ago}

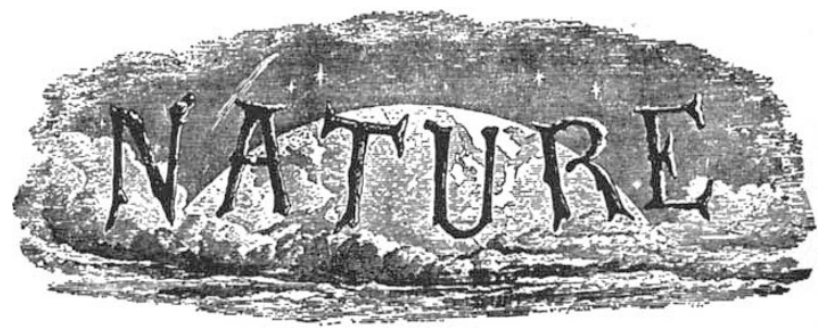

MR. BESSEMER'S SALOON STEAMER FOR THE CHANNEL PASSAGE

THE prevention of sea-sickness by means of a swinging cabin has nothing novel about it, but the originality and inventive merit in the suspended saloon devised by Mr. Bessemer, and now about to be actually constructed in a ship specially designed for it by Mr. Reed, the late Chief Constructor of the Navy, are of the highest order. The association of those names is in itself a sufficient guarantee that the idea will be carried into execution with complete security as respects the safety of the passengers and the seaworthiness of the ship, and a full knowledge of the scientific principles involved.

On the whole, while we are unwilling to commit ourselves to any prophecy, either of complete success or of partial failure, we think very favourably of the proposal. As a mere scientific experiment it is one of the very highest interest. As a practical design it offers a sure prospect of realising a large part of its intention, and a fair prospect of attaining a high degree of success. We feel confident that it will save a great many who would otherwise suffer, from being sea-sick at all, but we can hardly hope that there will not be sufficient residual motion in very heavy weather to cause some degree of uneasiness to very sensitive persons; nor would we venture to predict what will be the numerical reduction in the proportion of persons relieved from sickness, or the amount of alleviation to those not wholly saved from it.

From Nature, 7, 41 and 42, November 21, 1872. 